\title{
Electrochemical degradation of nitrofurans furazolidone by cathode: Characterization, pathway and antibacterial activity analysis
}

\author{
Deyong Kong ${ }^{\mathrm{a}}$, Bin Liang ${ }^{\mathrm{b}}$, Hui Yun ${ }^{\mathrm{b}}$, Jincai Ma ${ }^{\mathrm{c}}$, Zhiling Li $^{\mathrm{a}}$, Aijie Wang ${ }^{\mathrm{a}, \mathrm{b}, *}$, Nanqi Ren ${ }^{\mathrm{a}, *}$ \\ ${ }^{a}$ State Key Laboratory of Urban Water Resource and Environment, Harbin Institute of Technology, Harbin 150090, PR China \\ ${ }^{\mathrm{b}}$ Key Laboratory of Environmental Biotechnology, Research Center for Eco-Environmental Sciences, Chinese Academy of Sciences, Beijing 100085, PR China \\ ${ }^{\mathrm{C}}$ College of Environment and Resources, Jilin University, Changchun 130021, PR China
}

\section{H I G H L I G H T S}

- The cathodic degradation of nitrofurans furazolidone (FZD) was achieved.

- The cathodic degradation pathway of FZD including open loop degradation was proposed.

- Different applied cathode potentials were associated with FZD degradation products composition.

- The cathodic degradation of FZD eliminated its antibacterial activity.

\section{A R T I C L E I N F O}

\section{Article history:}

Received 7 September 2014

Received in revised form 21 October 2014

Accepted 26 October 2014

Available online 1 November 2014

\section{Keywords:}

Nitrofurans antibiotics

Furazolidone degradation

Cathode potential

Antibacterial activity elimination
G R A P H I C A L A B S T R A C T

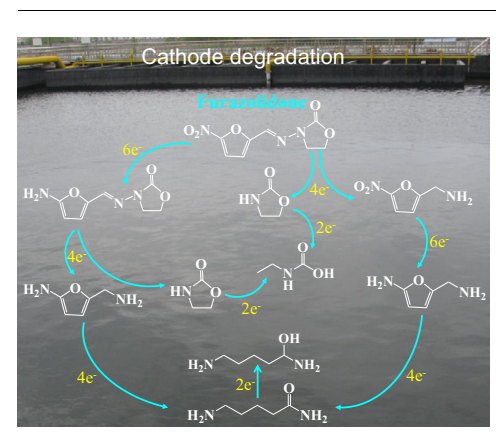

\begin{abstract}
A B S T R A C T
Antibiotics existing in wastewaters must be degraded to eliminate its antibacterial activity before discharging into the environment. Electrochemical reduction by continuous electrons supply can degrade various refractory pollutants, however, the information about the feasibility and characterization of the cathodic degradation of nitrofurans antibiotic furazolidone (FZD) is scarce. Here, we investigated the degradation of FZD using a poised cathode electrochemical reactor. The cyclic voltammetry (CV) preliminarily proved the feasibility of FZD degradation on cathode. In contrast to the different buffer solutions concentrations, buffer types, and initial FZD concentrations which only had obvious impact on the FZD degradation efficiency, different cathode potentials had significant effects both on the FZD degradation efficiency and degradation products composition. Catholyte PBS could be replaced by $\mathrm{Na}_{2} \mathrm{CO}_{3}-\mathrm{NaHCO}_{3}$ and $\mathrm{NaCl}$ buffer solution for the FZD degradation. The cathodic degradation pathway of FZD was proposed based on intermediate products analysis. When the cathode potential was lower than $-0.75 \mathrm{~V}$, both the furan ring and oxazole ring of FZD were destroyed to generate linear chain products after $\mathrm{N}-\mathrm{N}$ bond disconnection, suggesting that the high toxic biological metabolite of FZD, 3-amino-2-oxazolidinone (AOZ) could be detoxified by cathodic degradation. This study suggests that the electrochemical reduction could serve as a potential strategy for the treatment of FZD and AOZ containing wastewater.
\end{abstract}

(c) 2014 Elsevier B.V. All rights reserved.
* Corresponding authors at: State Key Laboratory of Urban Water Resource and Environment, Harbin Institute of Technology, Harbin 150090, PR China (A. Wang) Tel./fax: +86 45186282195 .

E-mail addresses: waj0578@hit.edu.cn (A. Wang), rnq@hit.edu.cn (N. Ren).

\section{Introduction}

Pharmaceuticals and personal care products (PPCPs) have been classified as emerging contaminants ubiquitously found in the aquatic environment in China and other countries [1,2]. As one of the most important pharmaceuticals, antibiotics have been widely 
used for human and animals since last century. China, the world's largest producer and consumer of pharmaceutical products, consumes more than 25,000 tons antibiotics annually [3]. Furazolidone (FZD), namely 3-(5-nitrofurfurylideneamino)-2-oxazolidinone, is a typical example of nitrofurans antibiotics, has been widely used for more than 30 years as an antibacterial and antiprotozoal feed additive for poultry, cattle and farmed fish as well as human medicine for the eradication of Helicobacter pylori [4]. Long-term studies with experimental animals indicated the mutagenic, genotoxic and potentially carcinogenic characteristics of FZD and its metabolite 3-amino-2-oxazolidinone (AOZ) [5]. Thus, its utilization has been banned in food-producing animals by European Union and Ministry of Agriculture of China in 1995 and 2002, respectively. However, due to the low production cost and high effectiveness of FZD, it is still being illegally used in a relatively large scale across the world, particularly in developing countries [6]. In general, animals and human had a very low assimilation rate of the FZD, thus a majority of the FZD used in farms and aquaculture was finally released into the environments [4]. As a result, FZD residues and its high toxic biological metabolite AOZ were frequently detected in some aquatic species, aquatic products, pond water and sediments [5,7-9]. Thus, it is necessary to detoxify FZD and AOZ in contaminated environments or municipal wastewaters.

Generally, bacterial degradation of FZD suffered from lower degradation rates due to its antimicrobial nature $[4,10]$, while physical-chemical methods such as electron irradiation are needed to provide more energy required for FZD degradation [11]. The electrochemical reduction is an emerging technology that could reductively degrade various refractory pollutants with features of higher removal efficiency, environmental friendly and low-cost [12-18]. The existence of FZD in the wastewaters or surface water environments must be degraded to eliminate its antibacterial activity. The electrochemistry based method for the removal of various antibiotic chloramphenicol, sulfonamides, trimethoprim, tetracycline, ceftriaxone, penicillin, and metronidazole by abiotic anode, bioanode, abiotic cathode or biocathode in electrochemical system has been studied extensively [19-25]. However, regarding the electrochemical degradation of nitrofurans FZD by cathode has not been well understood yet. Thus, it is necessary to conduct more experiments to elucidate the mechanisms involved in the detoxification of FZD and its high toxic metabolite AOZ in various wastewaters before their discharging into the environment.

This study discussed the effects of different cathode potentials, cathode buffer solutions and initial antibiotics concentrations on the degradation of antibiotics FZD by a poised cathode electrochemical reactor. Meanwhile, the cyclic voltammetry (CV) characterization, degradation pathways, and toxicity analysis of degradation products were also described. The aims of this study were to (i) characterize the cathodic degradation of FZD under different conditions; (ii) reveal the linkages between FZD degradation products and cathode potentials and (iii) confirm the cathodic degradation process which would eliminate the antibacterial activity of FZD. The results verified that the cathode providing electrons microenvironment could efficiently degrade and detoxify antibiotics FZD by applying tiny voltage, suggesting that the electrochemical reduction could serve as a potential pre-treatment or advanced treatment unit for antibiotics containing wastewaters.

\section{Materials and methods}

\subsection{Experimental setup}

The electrochemical reactors were constructed by assembling two equal-volume Lexan cubic chambers $(4 \mathrm{~cm} \times 4 \mathrm{~cm} \times 3 \mathrm{~cm})$ with a cylindrical cavity ( $3 \mathrm{~cm}$ in diameter and $4 \mathrm{~cm}$ in length) as described previously [26]. The chambers each had a $28 \mathrm{~mL}$ of internal volume and they were separated by a pretreated cation exchange membrane (Ultrex CMI-7000, Membranes International, Ringwood, NJ, USA). Graphite fiber brush $(2.5 \mathrm{~cm}$ in diameter and $2.5 \mathrm{~cm}$ in length, TOHO TENAX Co., Ltd., Tokyo, Japan) twisted by titanium wire ( $2 \mathrm{~mm}$ in diameter) (BaoJi XinLiTong Group Co., Ltd., China) worked as electrodes. The electrodes were pretreated with $1 \mathrm{M}$ hydrochloric acid for $24 \mathrm{~h}$ and then immersed in deionized water for another $24 \mathrm{~h}$, finally baked using muffle furnace (SX2-4-10G, Jinan Precise. Sci. Instru. Co., Ltd., China) at $450{ }^{\circ} \mathrm{C}$ for $30 \mathrm{~min}$. Cathode potential was poised by a potentiostat (WMPG1000K8 multichannel potentiostat, WonATech Co., Ltd., Seoul, South Korea). About $28 \mathrm{~mL}$ phosphate buffer solution (PBS, $50 \mathrm{mM}, 11.55 \mathrm{~g} / \mathrm{L} \mathrm{Na}_{2} \mathrm{HPO}_{4}$ and $2.77 \mathrm{~g} / \mathrm{L} \mathrm{NaH} \mathrm{PO}_{4}$ ) was added into the counter electrode chamber, while for working electrode chamber, $50 \mathrm{mM}$ PBS amended with $35 \mathrm{mg} / \mathrm{L}$ FZD was supplied, unless otherwise stated. Saturated calomel reference electrode (SCE) ( $0.247 \mathrm{~V}$ vs. standard hydrogen electrode (SHE), model-217, Shanghai Precise. Sci. Instru. Co., Ltd., China) was inserted into the cathode chamber. All of the potentials reported herein were already against SHE. The schematic diagram of the dual chamber electrochemical reactor used in this study has been shown in Fig. 1.

\subsection{Chemicals}

Furazolidone (FZD, $>98 \%$ purity) and high performance liquid chromatography (HPLC) grade methanol were purchased from Aladdin (Shanghai, China) and Sigma-Aldrich (St. Louis, MO, USA), respectively. GC derivatization regent $\mathrm{N}, \mathrm{O}$-Bis (trimethylsilyl) trifluoroacetamide (BSTAF, $\geqslant 99 \%$ purity) and catalyst pyridine (>99.9\% purity) were purchased from Sigma-Aldrich (St. Louis, MO, USA) and Aladdin (Shanghai, China), respectively. Other chemicals used in this study were of analytical grade. Ultrapure water used throughout the study was obtained from a Milli-Q Academic water purification system (Millipore, Bedford, MA, USA).

\subsection{Analytical methods}

Effluent samples from the cathode chamber (at 0th, 3rd, 9th, 24th and 48th $\mathrm{h}$ ) were filtered through a $0.22 \mu \mathrm{m}$ filter prior to HPLC analysis. The concentrations of FZD and its transformation products were measured using a reverse-phase HPLC system (model-2695, Waters, Milford, MA, USA) equipped with a C18 analytical column $(5 \mu \mathrm{m} 4.6 \times 250 \mathrm{~mm}$, Waters Co., USA) and a UV detector $(250 \mathrm{~nm})$. The separation was achieved by using mobile phase (methanol/ $\mathrm{H}_{2} \mathrm{O}, 50: 50 ; \mathrm{Vol} / \mathrm{Vol}$ ) at a flow rate of $0.8 \mathrm{~mL} /$

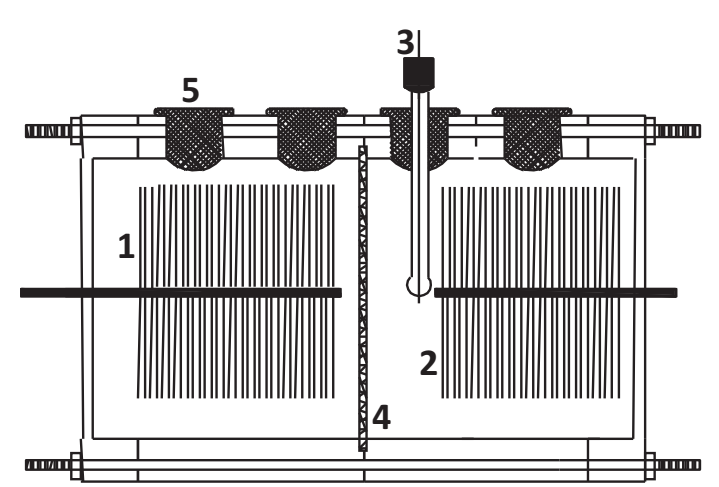

Fig. 1. The schematic diagram of electrochemical reactor used in this study. (1) Carbon brush anode; (2) carbon brush cathode; (3) saturated calomel reference electrode; (4) cation exchange membrane; (5) rubber stopple. 
min at $30{ }^{\circ} \mathrm{C}$ on the column. To identify the products during FZD degradation, a reversed phase liquid chromatography (model1200 , Agilent, USA) equipped with a quadrupole time of flight mass spectrometry (QTOFMS) (model-6520, Agilent, USA) detector system in the positive ion mode was used. The separation was performed on an Agilent Zorbax XDB C18 analytical column $(1.8 \mu \mathrm{m}$; $2.1 \times 100 \mathrm{~mm}$ ) using flow phase (methanol $/ \mathrm{H}_{2} \mathrm{O}, 50: 50 ; \mathrm{Vol} / \mathrm{Vol}$ ) at a flow rate of $0.15 \mathrm{~mL} / \mathrm{min}$ with UV detection at $250 \mathrm{~nm}$.

A gas chromatography-mass spectrometry (GC-MS) system equipped with an Agilent 7890A/5975C mass spectrometer detector and a HP-5 MS silica fused capillary column $(30 \mathrm{~m} \times$ $0.25 \mathrm{~mm} \times 0.25 \mu \mathrm{m}$ film thickness) was also used to identify the FZD degradation products. MS scan was performed under full scan model $(\mathrm{m} / \mathrm{z}$ of $30-300)$. The catholyte $(50 \mathrm{~mL})$ performed at $-1.25 \mathrm{~V}$ was taken on 24th $\mathrm{h}$ of an operational cycle, and extracted with equal volume ethyl acetate. The upper ethyl acetate layer was firstly dehydrated by anhydrous sodium sulfate and then was concentrated to $1 \mathrm{~mL}$ using a rotary evaporator at $50{ }^{\circ} \mathrm{C}$. Subsequently, $200 \mu \mathrm{L}$ of the sample was derived at room temperature with $200 \mu \mathrm{L}$ BSTAF as derivatization regent and $200 \mu \mathrm{L}$ pyridine as catalyst for indirect identification of polar FZD degradation intermediates. The operation conditions for GC-MS analysis has described previously [27].

To identify the extent to which FZD was degraded under different cathode potentials, cathode effluents sampled at 6th h or 24 th h with different cathode potentials supply $(-0.30 \mathrm{~V},-0.75 \mathrm{~V}$ and $-1.25 \mathrm{~V}$ ) were subjected to a scan by a UV spectrometer (Shimadzu UV2550 spectrometer, Kyoto, Japan). The scanning rate and wavelength range was $0.5 \mathrm{~nm} / \mathrm{s}$ and $200-450 \mathrm{~nm}$, respectively.

The FZD reduction efficiency $\left(\mathrm{Er}_{\mathrm{FZD}}\right.$, \%) was calculated based on the difference between influent and effluent FZD concentrations. The kinetics of FZD degradation was assumed to follow the apparent first-order reaction model as $C=C^{0} e^{-k t}$, where $C$ is FZD concentrations $(\mathrm{mg} / \mathrm{L})$ at time $t(\mathrm{~h})$ and $C^{0}$ is initial antibiotics concentrations (35 mg/L), unless otherwise stated. The rate constant $k\left(\mathrm{~h}^{-1}\right)$ was calculated according to the above mentioned formula and statistical analysis, namely two-tailed unpaired $t$-test, was also performed.

The cyclic voltammetry (CV) test was carried out using an electrochemical workstation (model-660D, CH Instruments Inc., Austin, TX, USA) equipped with a three-electrode system [28]. The glassy carbon electrode (GCE) (3 $\mathrm{mm}$ in diameter, GaossUnion Technology Co., Ltd., Wuhan, China) and the titanium wire (100 $\mathrm{mm}$ in length and $1 \mathrm{~mm}$ in diameter) acted as working and counter electrode, respectively. The SCE was the reference electrode. Cyclic voltammograms were recorded with the scan rate of $5 \mathrm{mV} / \mathrm{s}$ at $25^{\circ} \mathrm{C}$.

\subsection{Antibacterial activity assay}

The antibacterial activity of FZD and its corresponding degradation products to bacterial strains was evaluated based on their toxicity on the viabilities of Escherichia coli DH5 $\alpha$ (Takara Biotechnology Co., Ltd., Dalian, China) and Lactococcus lactis subsp. lactis bv. diacetylactis CCTCC AB2010211 (China Center for Type Culture Collection, Wuhan, China). E. coli DH5 $\alpha$ is a typical Gramnegative bacterium, which was selected as an indicative microbe not only for water quality monitoring but also for many antibiotic activity and pollutant degradation products toxicity analysis $[29,30]$. L. lactis CCTCC AB2010211 is a Gram-positive bacterium, which was reported to be sensitive to many kinds of antibiotics [31]. Luria-Bertani (LB) medium (tryptone $10 \mathrm{~g} / \mathrm{L}$, yeast extract $5 \mathrm{~g} / \mathrm{L}$ and $\mathrm{NaCl} 10 \mathrm{~g} / \mathrm{L}$ ) was used for cultivating E. coli and L. lactis. 3-fold-diluted sterile LB medium was mixed with filtered cathode effluents and adjusted $\mathrm{pH}$ to 7.0 prior to antimicrobial activity tests. The tested concentration for FZD was $35 \mathrm{mg} / \mathrm{L}$. The same medium without FZD and corresponding cathode effluents was served as controls. E. coli and L. lactis were cultivated under aerobic and anaerobic conditions, respectively.

During the antibacterial activity assay tests, samples were periodically taken within 24 or $60 \mathrm{~h}$ of incubation. Biomass was collected by centrifugation and resuspended with PBS $(50 \mathrm{mM}$; $\mathrm{pH}$ 7.0), and then was subjected to $\mathrm{OD}_{600 \mathrm{~nm}}$ measurement (Shimadzu UV2550 spectrometer, Kyoto, Japan). The apparent growth rate $\left(k, \mathrm{~h}^{-1}\right)$ within exponential phase for $E$. coli and $L$. lactis under different cultivation conditions referred to the equation as following: $k=\left(O D_{2}-O D_{1}\right) /\left(t_{2}-t_{1}\right)$, where $O D_{2}$ and $O D_{1}$ are the optical density measured at time $t_{2}$ and $t_{1}$ of exponential phase, respectively [32]. The antibacterial activity assay was performed in duplicate.

\section{Results and discussion}

\subsection{The $C V$ characterization of FZD}

CV test was employed to investigate the transformation of FZD in the cathode. The reduction potential of FZD on the cathode was started around $-0.15 \mathrm{~V}$ and peaked at ca. $-0.30 \mathrm{~V}$ (peak a), $-0.55 \mathrm{~V}$ (peak b) and $-0.90 \mathrm{~V}$ (peak c), respectively (Fig. 2). The results demonstrated that FZD can be reduced when the cathode potential was lower than $-0.15 \mathrm{~V}$ and the reduction current was much greater when the cathode potential was more negative, which means FZD can be reduced more quickly. It also manifested that there were three main degradation products at three different cathode potentials which were likely associated with three main peak currents (peaks a, b and c). Additionally, the reduction current sharply increased when the cathode potential was lower than $-0.90 \mathrm{~V}$, suggesting that FZD degradation took place more quickly and hydrogen evolution reaction also obviously happened at such low cathode potential.

\subsection{The degradation of FZD under different cathode potentials}

According to the $\mathrm{CV}$ results, five different cathode potentials $(-0.15 \mathrm{~V},-0.30 \mathrm{~V},-0.45 \mathrm{~V},-0.75 \mathrm{~V}$ and $-1.25 \mathrm{~V})$ were selected to investigate the influences of different cathode potentials on the degradation efficiency and rate of FZD. FZD can be degraded efficiently under different cathode potentials, especially with lower potentials (Fig. 3A). The results indicated that FZD degradation reactions were fitted pseudo-first order kinetics well $\left(r^{2}>0.977\right)$. The $k$ significantly increased with the decrease of cathode potentials (from $0.300 \pm 0.036$ to $0.867 \pm 0.046$ ), and FZD degradation efficiency at $3 \mathrm{~h}\left(\mathrm{Er}_{3 \mathrm{~h}}\right)$ or $9 \mathrm{~h}\left(\mathrm{Er}_{9 \mathrm{~h}}\right)$ also had similar increase trend though some comparative results had no obvious differences

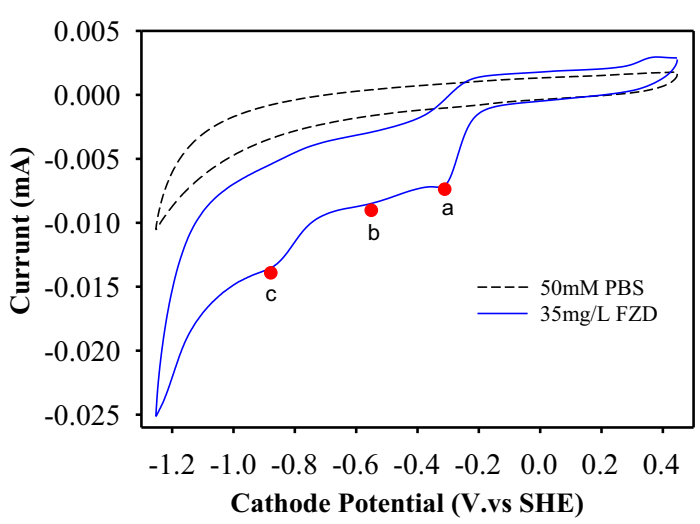

Fig. 2. The cyclic voltammogram of $35 \mathrm{mg} / \mathrm{L} \mathrm{FZD} \mathrm{in} \mathrm{the} \mathrm{presence} \mathrm{of} 50 \mathrm{mM}$ PBS. The data was obtained from the second run of $\mathrm{CV}$. 

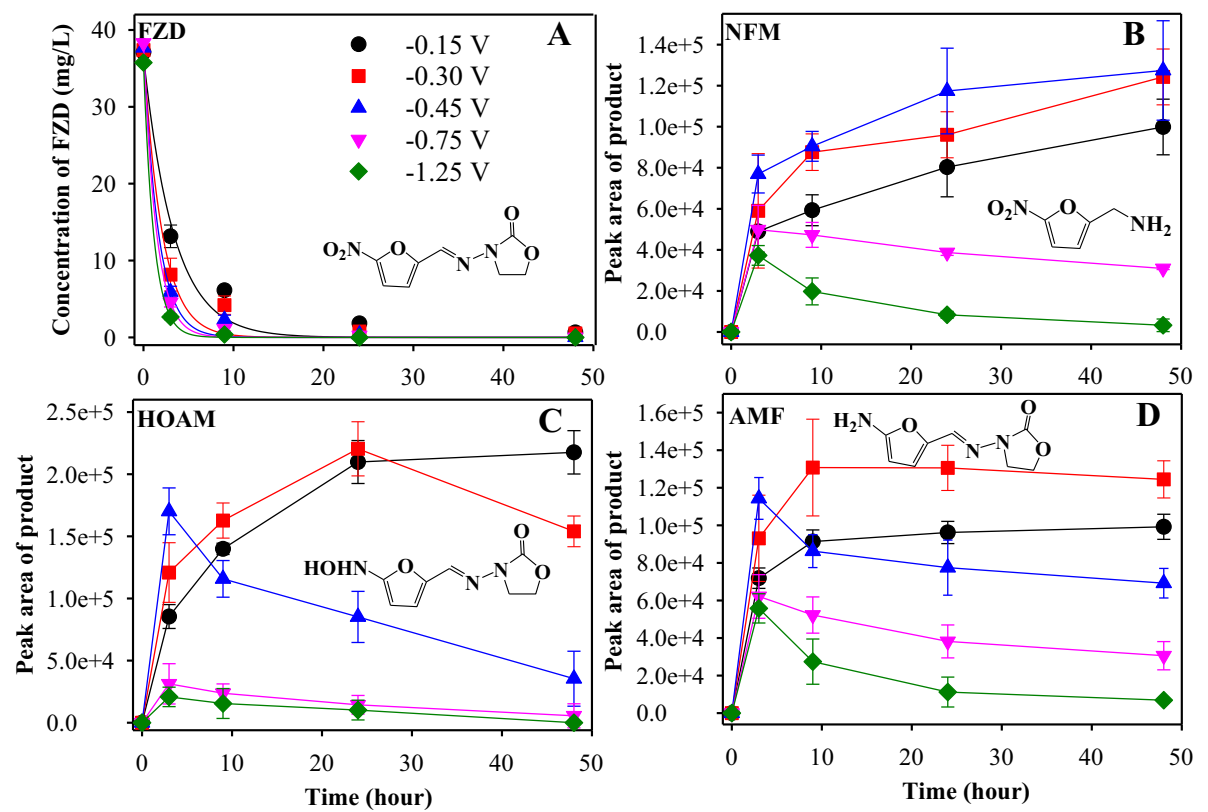

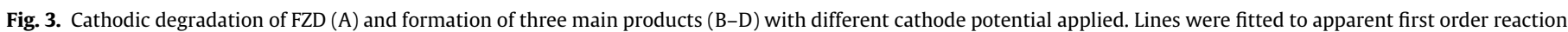
model for the kinetic analysis.

(Table 1). The $\mathrm{Er}_{9 \mathrm{~h}}$ at $-0.45 \mathrm{~V}$ or lower had significant higher efficiency than that of $-0.15 \mathrm{~V}$ (increased by $10-15 \%, P<0.01$ ). These results strongly indicated the important influences of different cathode potentials on the degradation efficiency and rate of FZD.

\subsection{The FZD degradation products dynamics under different cathode potentials}

During FZD degradation in this study, three main reduced products namely 3-(5-hydroxylaminefurfurylideneamino)-2-oxazolidinone (HOAM), 3-(5-aminefurfurylideneamino)-2-oxazolidinone (AMF) and $\mathrm{N}-\mathrm{N}$ fraction product (5-nitro-2-furyl) methanamine (NFM) have been detected by HPLC analysis (data not shown). The peak area of HOAM, AMF and NFM firstly increased and then decreased in turn when the cathode potentials were poised at
$-0.30 \mathrm{~V},-0.45 \mathrm{~V}$ and $-0.75 \mathrm{~V}$, respectively (Fig. 3B-D). It means that these products could be further degraded by lowering cathode potential and the order of cathode reducibility for these products is: $\mathrm{HOAM}>\mathrm{AMF}>\mathrm{NFM}$. The peak areas of these three products were obviously accumulated when the cathode potential was poised at $-0.15 \mathrm{~V}$ or $-0.30 \mathrm{~V}$ within $48 \mathrm{~h}$. When the cathode potential grew up to $-0.45 \mathrm{~V}$, the HOAM product could be reduced to AMF product, and AMF was firstly accumulated and then slowly dropped within $48 \mathrm{~h}$ (Fig. 3C and D). The peak area of the NFM continuously rose when the cathode potential was above $-0.75 \mathrm{~V}$ whilst obviously decreased under the cathode potential lower than $-0.75 \mathrm{~V}$. The peak area of HOAM, AMF and NFM decreased to 0 , 6905 and 3273, respectively at the cathode potential of $-1.25 \mathrm{~V}$. Compared with the reactors poised at $-0.30 \mathrm{~V}$, the peak area of HOAM, AMF and NFM at the cathode potential of $-1.25 \mathrm{~V}$ reduced by $100 \%, 93.82 \%$ and $97.36 \%$, respectively (Fig. 3B-D). Thus, these

Table 1

The respective $\mathrm{Er}_{3 \mathrm{~h}}, \mathrm{Er}_{9 \mathrm{~h}}, k$ and $r^{2}$ of the electrochemical degradation of FZD under different cathode conditions.

\begin{tabular}{|c|c|c|c|c|}
\hline & $\mathrm{Er}_{3 \mathrm{~h}}(\%)$ & $\mathrm{Er}_{9 \mathrm{~h}}(\%)$ & $k\left(\mathrm{~h}^{-1}\right)$ & $r^{2}$ \\
\hline \multicolumn{5}{|l|}{ Cathode potentials } \\
\hline$-0.15 \mathrm{~V}$ & $0.646 \pm 0.040^{\mathrm{a}}$ & $0.835 \pm 0.011^{\mathrm{ab}}$ & $0.300 \pm 0.036^{\mathrm{a}}$ & $0.9774 \pm 0.0055$ \\
\hline$-0.30 \mathrm{~V}$ & $0.781 \pm 0.057^{\mathrm{bf}}$ & $0.888 \pm 0.032^{\mathrm{bf}}$ & $0.483 \pm 0.085^{\mathrm{b}}$ & $0.9838 \pm 0.0090$ \\
\hline$-0.45 \mathrm{~V}$ & $0.843 \pm 0.020^{\mathrm{bc}}$ & $0.939 \pm 0.015^{\mathrm{cf}}$ & $0.610 \pm 0.040^{\mathrm{bc}}$ & $0.9951 \pm 0.0028$ \\
\hline$-0.75 \mathrm{~V}$ & $0.881 \pm 0.015^{\mathrm{df}}$ & $0.971 \pm 0.007^{\mathrm{df}}$ & $0.709 \pm 0.045^{\mathrm{d}}$ & $0.9989 \pm 0.0005$ \\
\hline$-1.25 \mathrm{~V}$ & $0.925 \pm 0.010^{\mathrm{ef}}$ & $0.989 \pm 0.006^{\text {de }}$ & $0.867 \pm 0.046^{\text {de }}$ & $0.9997 \pm 0.0001$ \\
\hline \multicolumn{5}{|l|}{ Buffer solutions } \\
\hline $50 \mathrm{mM}$ PBS & $0.771 \pm 0.046^{\mathrm{ab}}$ & $0.875 \pm 0.010^{\mathrm{ab}}$ & $0.466 \pm 0.073^{\mathrm{ab}}$ & $0.9804 \pm 0.0028$ \\
\hline $25 \mathrm{mM}$ PBS & $0.746 \pm 0.017^{\mathrm{b}}$ & $0.847 \pm 0.022^{\text {bef }}$ & $0.416 \pm 0.016^{\mathrm{b}}$ & $0.9708 \pm 0.0104$ \\
\hline $10 \mathrm{mM}$ PBS & $0.675 \pm 0.024^{\mathrm{cdf}}$ & $0.833 \pm 0.013^{\mathrm{cf}}$ & $0.325 \pm 0.029^{c}$ & $0.9731 \pm 0.0025$ \\
\hline $2 \mathrm{mM}$ PBS & $0.598 \pm 0.033^{\mathrm{de}}$ & $0.792 \pm 0.024^{\mathrm{de}}$ & $0.242 \pm 0.018^{\mathrm{d}}$ & $0.9609 \pm 0.0183$ \\
\hline $50 \mathrm{mM} \mathrm{NaCl}$ & $0.753 \pm 0.016^{\mathrm{abf}}$ & $0.873 \pm 0.025^{\mathrm{bcd}}$ & $0.435 \pm 0.031^{\mathrm{bc}}$ & $0.9794 \pm 0.0085$ \\
\hline $50 \mathrm{mM} \mathrm{Na}{ }_{2} \mathrm{CO}_{3}-\mathrm{NaHCO}_{3}$ & $0.678 \pm 0.053^{\text {abdf }}$ & $0.843 \pm 0.025^{\mathrm{bcd}}$ & $0.335 \pm 0.067^{\mathrm{bcd}}$ & $0.9699 \pm 0.0062$ \\
\hline \multicolumn{5}{|l|}{ Initial concentrations } \\
\hline $35 \mathrm{mg} / \mathrm{L}$ & $0.754 \pm 0.035^{\mathrm{a}}$ & $0.873 \pm 0.020^{\mathrm{a}}$ & $0.454 \pm 0.030^{\mathrm{a}}$ & $0.9795 \pm 0.0054$ \\
\hline $10 \mathrm{mg} / \mathrm{L}$ & $0.676 \pm 0.015^{\mathrm{b}}$ & $0.805 \pm 0.026^{\mathrm{b}}$ & $0.311 \pm 0.025^{\mathrm{b}}$ & $0.9589 \pm 0.0122$ \\
\hline $1 \mathrm{mg} / \mathrm{L}$ & $0.537 \pm 0.110^{\mathrm{ab}}$ & $0.769 \pm 0.038^{\mathrm{bc}}$ & $0.230 \pm 0.029^{\mathrm{ab}}$ & $0.9444 \pm 0.0342$ \\
\hline
\end{tabular}

Group with the same letters are not significantly different from each other at the 0.05 level. 
products were almost completely degraded to linear chain products at this low cathode potential.

\subsection{The identification of FZD degradation products}

FZD degradation products mentioned above were identified by LC-QTOFMS and GC-MS analysis. When the cathode potential was poised at $-0.30 \mathrm{~V}$, three main furan ring-containing products which had prominent protonated molecular ion at $\mathrm{m} / \mathrm{z} 164.93$ $[\mathrm{M}+\mathrm{Na}]^{+}, 218.05[\mathrm{M}+\mathrm{Na}]^{+}$and $234.03[\mathrm{M}+\mathrm{Na}]^{+}$were preliminarily identified as NFM, AMF and HOAM (Fig. 4A), respectively. When the cathode potential was placed at $-1.25 \mathrm{~V}$, two linear chain products had prominent protonated molecular ion at $\mathrm{m} / \mathrm{z} 138.91$ $[\mathrm{M}+\mathrm{Na}]^{+}$and $140.90[\mathrm{M}+\mathrm{Na}]^{+}$, and they were preliminarily identified as 5-amine-2-furaldehyde semicarbazone and 1,5-diaminopentan-2-ol by LC-QTOFMS analysis (Fig. 3A), indicating that this low cathode potential could open the furan ring of FZD. Additionally, the GC-MS results showed that $-1.25 \mathrm{~V}$ cathode potential could degrade the 2-oxazolidone to generate linear chain product (Fig. 4B). These results indicated that the disparity of FZD degradation products depended on the different cathode potentials. UV scan results also demonstrated that two characteristic UV absorption peak for FZD at $375 \mathrm{~nm}$ and $260 \mathrm{~nm}$ completely disappeared at $-1.25 \mathrm{~V}$ mode but some corresponding products was still existent under $-0.75 \mathrm{~V}$ or $-0.30 \mathrm{~V}$ (Fig. 5), indicating that low cathode potential contributed to the further degradation of FZD to linear chain products.

Collectively, there were three main products (HOAM, AMF and NFM) generated from FZD degradation between the cathode potential of $-0.15 \mathrm{~V}$ and $-0.45 \mathrm{~V}$ (Fig. 3B-D). When the cathode potential fallen to $-1.25 \mathrm{~V}$, both the furan ring and oxazole ring of FZD were destroyed to generate three identified linear chain products after the N-N bond disconnection (Fig. 4). The FZD cathodic degradation pathway was proposed in Fig. 6 based on the results in this study and other previous reports [33,34]. Cathodic degradation of FZD did not generate high toxic AOZ, which generally produced from biological metabolism of FZD [8]. Importantly, 2-oxazolidone had similar chemical structure as AOZ (3-amino-2-oxazolidinone), suggesting that AOZ could be detoxified by cathodic degradation carried out in this study. Previous studies showed that electron irradiation method could degrade FZD and AOZ by applying high energy [11,35]. In addition, ozonation was proposed for the

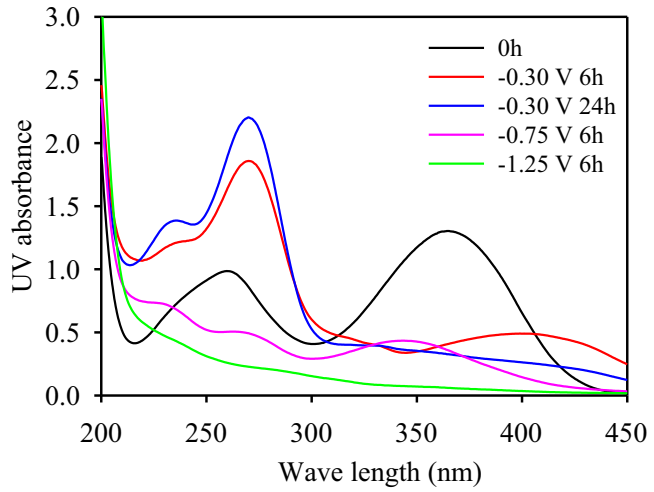

Fig. 5. UV-visible spectrum of the FZD and its degradation effluents under different cathode potentials with selected times.

efficient degradation of other nitrofurans furaltadone at acidic ( $\mathrm{pH}$ of 4.0) or alkaline ( $\mathrm{pH}$ of 12.8) conditions [36]. However, our results indicated that the cathode providing electrons microenvironment could efficiently degrade and detoxify antibiotics FZD and $\mathrm{AOZ}$ analogue, 2-oxazolidone under the neutral condition, by applying relatively lower voltage.

\subsection{The degradation of FZD under different buffer solutions}

Buffer solutions play key roles in microbial fuel cells and microbial electrolysis cells, which not only keep electrolyte $\mathrm{pH}$ stable but also supplies conductivity for hydrogen proton transfer. In consideration of the varied conductivity of practical wastewaters, it is meaningful to estimate the pollutant removal efficiency and stability by electrochemical reduction under different buffer solutions concentrations/types. Six kinds of different buffer solutions concentrations/types including $50 \mathrm{mM}$ PBS, $25 \mathrm{mM}$ PBS, $10 \mathrm{mM}$ PBS, $2 \mathrm{mM}$ PBS, $50 \mathrm{mM} \mathrm{NaCl}$ and $50 \mathrm{mM} \mathrm{Na} \mathrm{CO}_{3}-\mathrm{NaHCO}_{3}$ were tested for the cathodic degradation of FZD. When the PBS concentration changed from $50 \mathrm{mM}$ to $25 \mathrm{mM}$, the $\mathrm{Er}_{3 \mathrm{~h}}, \mathrm{Er}_{9 \mathrm{~h}}$ and $k$ of FZD degradation was not noticeably differed (Table $1, P>0.27$ ). However, $10 \mathrm{mM}$ and $2 \mathrm{mM}$ PBS displayed obvious decrease of $\mathrm{Er}_{3 \mathrm{~h}}$ and $k$ of FZD degradation compared with the results of $25 \mathrm{mM}$ or $50 \mathrm{mM}$ PBS conditions $(P<0.05)$. The $50 \mathrm{mM}$ PBS mode ranked the highest $k(0.466 \pm 0.073)$, which was nearly two times of the

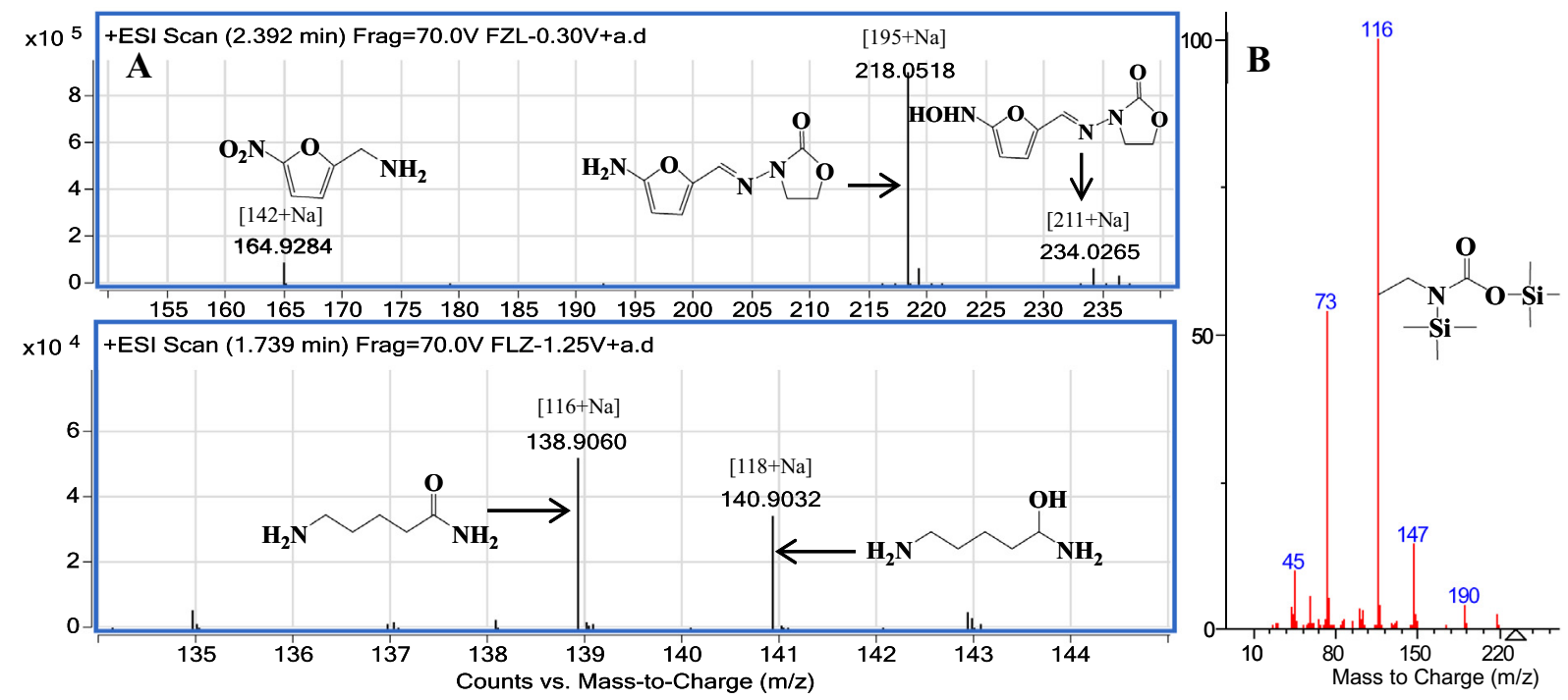

Fig. 4. The LC-MS (A) and GC-MS (B) profiles of the FZD degradation products by poised cathode potential of $-0.30 \mathrm{~V}$ and $-1.25 \mathrm{~V}$. 


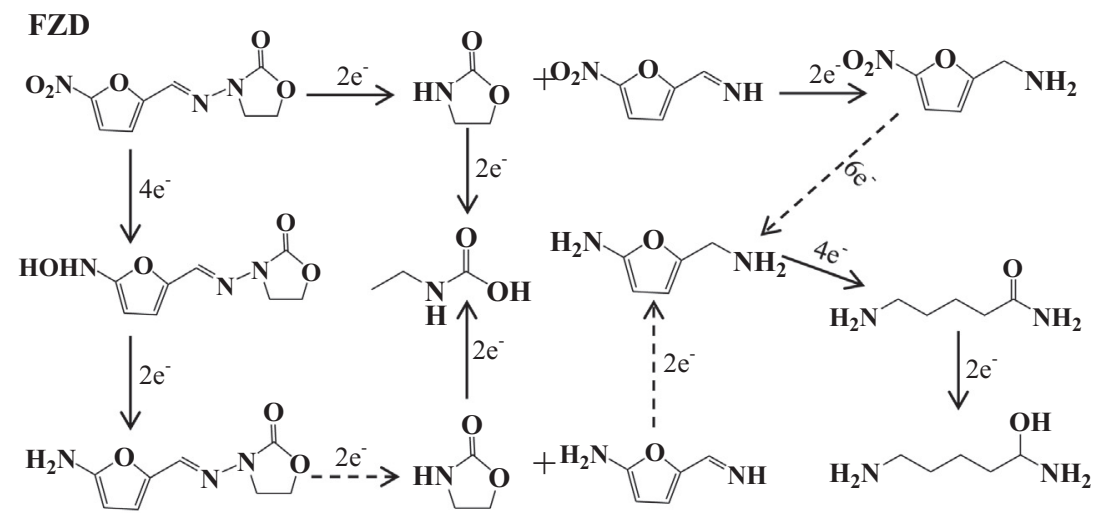

Fig. 6. The proposed pathway of the cathodic degradation of FZD. Dotted arrows indicates the occurred reaction was presumed in this study.

$k$ corresponding to the $2 \mathrm{mM}$ PBS mode $(0.242 \pm 0.018, P=0.033)$. These results indicated that the PBS concentrations had significant influence on the FZD degradation efficiency and rate when the concentration of PBS decreased over half of $50 \mathrm{mM}$. Contrasted with $50 \mathrm{mM}$ PBS mode, two other buffer solutions $50 \mathrm{mM} \mathrm{NaCl}$ and $50 \mathrm{mM} \mathrm{Na} \mathrm{CO}_{3}-\mathrm{NaHCO}_{3}$ modes showed no significant different FZD degradation efficiency and rate though the $50 \mathrm{mM} \mathrm{Na}_{2} \mathrm{CO}_{3}-$ $\mathrm{NaHCO}_{3}$ mode had relative lower $k, \mathrm{Er}_{3 \mathrm{~h}}$ and $\mathrm{Er}_{9 \mathrm{~h}}$ (Table 1, $P>0.10$ ). In addition, $\mathrm{CV}$ test showed that the reaction currents of FZD degradation in $25 \mathrm{mM}$ PBS, $50 \mathrm{mM}$ PBS, $50 \mathrm{mM} \mathrm{NaCl}$ and $50 \mathrm{mM} \mathrm{Na} \mathrm{CO}_{3}-\mathrm{NaHCO}_{3}$ buffer solutions had relatively higher peak currents than those of $10 \mathrm{mM}$ PBS and $2 \mathrm{mM}$ PBS modes at $-0.30 \mathrm{~V}$ (Fig. 7A), which was in concert with the degradation efficiency differences among different cathode buffer solutions concentrations/types (Table 1 ). These results together indicated that different PBS concentrations had obvious impact on the FZD degradation. Moreover, catholyte PBS could be replaced by $\mathrm{Na}_{2} \mathrm{CO}_{3}-\mathrm{NaHCO}_{3}$ and $\mathrm{NaCl}$ buffer solution for the FZD degradation.

\subsection{The degradation of FZD under different initial concentrations}

Three different initial concentrations $(35,10$ or $1 \mathrm{mg} / \mathrm{L})$ were studied for the FZD degradation. The results showed that $35 \mathrm{mg} / \mathrm{L}$ mode had the most highest $k(0.454 \pm 0.030, P<0.004)$ and the $\mathrm{Er}_{3 \mathrm{~h}}(0.754 \pm 0.035 \%, P<0.07)$ and $\mathrm{Er}_{9 \mathrm{~h}}(0.873 \pm 0.020 \%, P<0.03)$ among the three tested initial concentrations, while $1 \mathrm{mg} / \mathrm{L}$ initial concentration resulted in the lowest $k(0.230 \pm 0.029, P<0.025)$ and $\mathrm{Er}_{3 \mathrm{~h}}(0.537 \pm 0.110 \%)$ and $\mathrm{Er}_{9 \mathrm{~h}}(0.769 \pm 0.038 \%)$ though some comparative results had no significant differences (Table 1 ). CV test also showed that the reaction current of $35 \mathrm{mg} / \mathrm{L}$ FZD degradation had obvious higher peak current than those of $10 \mathrm{mg} / \mathrm{L}$ FZD and $1 \mathrm{mg} / \mathrm{L}$ FZD modes at $-0.30 \mathrm{~V}$ (Fig. 7B), which was agreed with the FZD degradation results among different initial FZD concentrations (Table 1). Interestingly, $10 \mathrm{mg} / \mathrm{L}$ FZD and $1 \mathrm{mg} / \mathrm{L}$ FZD modes had nearly the same reaction current. These results indicated that initial FZD concentrations had a significant impact on the FZD degradation rate and efficiency.

\subsection{Toxicity assessment of the FZD degradation products}

The antibacterial activity assay was performed using two selected bacterial strains (E. coli DH5 $\alpha$ and L. lactis). The growth of both strains was completely inhibited in the presence of $35 \mathrm{mg} / \mathrm{L}$ FZD, but was not in the presence of its degradation products under two tested cathode potentials $-0.30 \mathrm{~V}$ and $-1.25 \mathrm{~V}$. Concretely, the FZD degradation products at $-1.25 \mathrm{~V}$ has relatively better $E$. coli growth trend than that at $-0.30 \mathrm{~V}$, suggesting that $-1.25 \mathrm{~V}$ cathode effluents can be further detoxified compared to FZD degradation under relatively higher cathode potential $-0.30 \mathrm{~V}$. While two cathode potentials effluents showed nearly same growth trend for anaerobic growth of L. lactis. Compared to their growth in blank control experiments (normal medium containing no FZD or corresponding degradation products), E. coli and L. lactis displayed growth curves not significantly different with those in the cathode effluents diluted by LB medium (Fig. 8). Additionally, the E. coli apparent growth rate (between 4 and $12 \mathrm{~h})$ in FZD, FZD degradation product $(-0.30 \mathrm{~V}$ cathode potential), FZD degradation product $(-1.25 \mathrm{~V}$ cathode potential) containing and normal 3-fold-diluted LB medium was 0.0008 $\pm 0.0002, \quad 0.0422 \pm 0.0011, \quad 0.0508 \pm 0.0004$ and $0.0596 \pm$
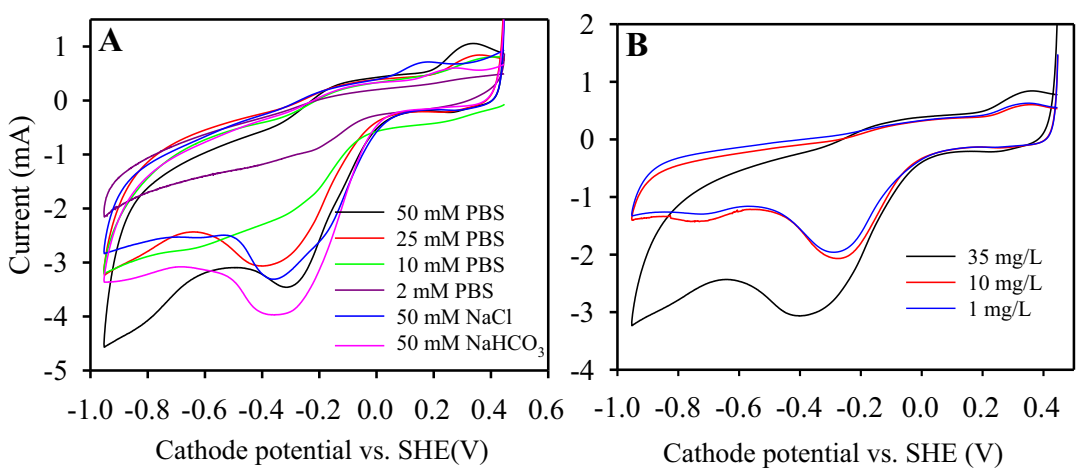

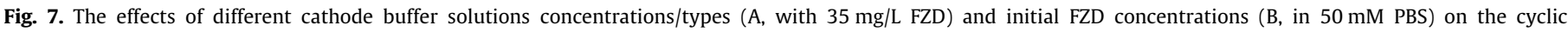
voltammograms characteristics for the FZD degradation. The data was obtained from the second run of CV. 


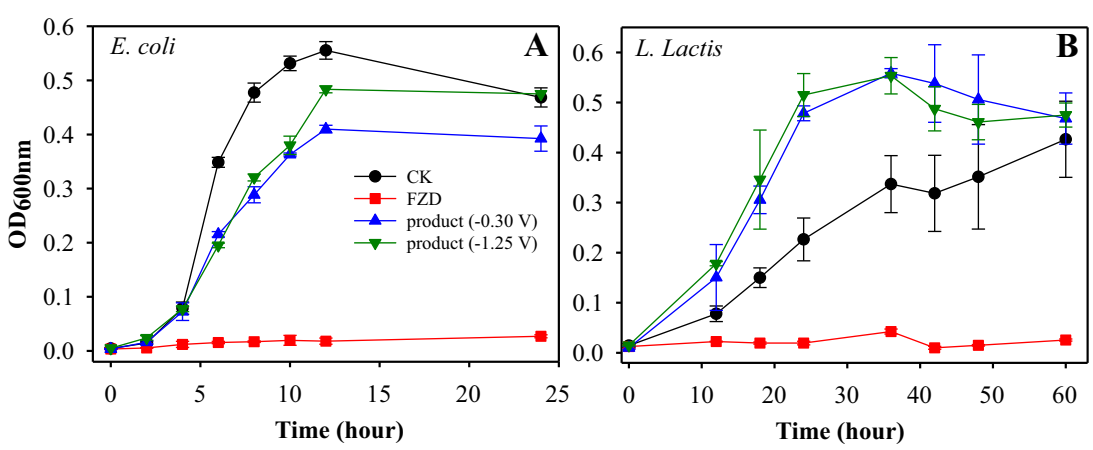

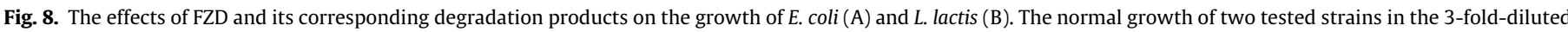
LB medium was also evaluated.

$0.0006 \mathrm{~h}^{-1}$, respectively. The $L$. lactis apparent growth rate (between 12 and $36 \mathrm{~h})$ in FZD, FZD degradation product $(-0.30 \mathrm{~V}$ cathode potential), FZD degradation product $(-1.25 \mathrm{~V}$ cathode potential) containing and normal 3-fold-diluted LB medium was $0.0008 \pm 0.0002, \quad 0.0170 \pm 0.0024, \quad 0.0156 \pm 0.0020$ and 0.0108 $\pm 0.0018 \mathrm{~h}^{-1}$, respectively. These results together indicated that the cathodic degradation of FZD could eliminate the antibacterial activity of FZD and increase the growth rate of tested strains, which has meaningful ecological significances for the treatment of FZD containing wastewaters.

\section{Conclusions}

The cathodic degradation feasibility for nitrofurans antibiotics FZD was demonstrated. Different buffer solutions concentrations/ types and initial FZD concentrations only had obvious influences on the FZD degradation efficiency, while different applied cathode potentials was associated with FZD degradation products composition. Catholyte PBS could be replaced by $\mathrm{Na}_{2} \mathrm{CO}_{3}-\mathrm{NaHCO}_{3}$ and $\mathrm{NaCl}$ buffer solution for the FZD degradation. The cathodic degradation pathway of FZD including open loop degradation was proposed. When the cathode potential was lower than $-0.75 \mathrm{~V}$, both the furan ring and oxazole ring of FZD were destroyed to generate linear chain products. Cathodic degradation process contributed to the elimination of the FZD antibacterial activity.

\section{Acknowledgments}

This work was supported by the National Science Foundation for Distinguished Young Scholars of China (No. 51225802), the National Natural Science Foundation of China (No. 51178140), the State Key Laboratory of Urban Water Resource and Environment of HIT (No. 2013DX02) and the Hundred Talents Program of the Chinese Academy of Sciences (No. 29BR2013001).

\section{References}

[1] Q.W. Bu, B. Wang, J. Huang, S.B. Deng, G. Yu, Pharmaceuticals and personal care products in the aquatic environment in China: a review, J. Hazard. Mater. 262 (2013) 189-211.

[2] J.L. Liu, M.H. Wong, Pharmaceuticals and personal care products (PPCPs): a review on environmental contamination in China, Environ. Int. 59 (2013) 208224.

[3] W.H. Xu, G. Zhang, S.C. Zou, X.D. Li, Y.C. Liu, Determination of selected antibiotics in the Victoria Harbour and the Pearl River, South China using highperformance liquid chromatography-electrospray ionization tandem mass spectrometry, Environ. Pollut. 145 (2007) 672-679.

[4] W.W. Zhang, Z.L. Niu, K. Yin, F. Liu, L.X. Chen, Degradation of furazolidone by bacteria Acinetobacter calcoaceticus T32, Pseudomonas putida SP1 and Proteus mirabilis V7, Int. Biodeterior. Biodegrad. 77 (2013) 45-50.

[5] J. Song, H. Yang, Y.Z. Wang, W.H. Si, A.P. Deng, Direct detection of 3-amino-5methylmorpholino-2-oxazolidinone (AMOZ) in food samples without derivatisation step by a sensitive and specific monoclonal antibody based ELISA, Food Chem. 135 (2012) 1330-1336.

[6] K. Yin, W.W. Zhang, L.X. Chen, Pyoverdine secreted by Pseudomonas aeruginosa as a biological recognition element for the fluorescent detection of furazolidone, Biosens. Bioelectron. 51 (2014) 90-96.

[7] G.J. Yang, W.J. Jin, L.P. Wu, Q.Q. Wang, H.X. Shao, A.J. Qin, B. Yu, D.M. Li, B.L. Cai, Development of an impedimetric immunosensor for the determination of 3 amino-2-oxazolidone residue in food samples, Anal. Chim. Acta 706 (2011) $120-127$.

[8] E.L.E. Jester, A. Abraham, Y.S. Wang, K.R. El Said, S.M. Plakas, Performance evaluation of commercial ELISA kits for screening of furazolidone and furaltadone residues in fish, Food Chem. 145 (2014) 593-598.

[9] W.H. Yu, T.S. Chin, H.T. Lai, Detection of nitrofurans and their metabolites in pond water and sediments by liquid chromatography (LC)-photodiode array detection and LC-ion spray tandem mass spectrometry, Int. Biodeterior. Biodegrad. 85 (2013) 517-526.

[10] B. Halling-Sorensen, S.N. Nielsen, P.F. Lanzky, F. Ingerslev, H.C.H. Lutzhoft, S.F. Jorgensen, Occurrence, fate and effects of pharmaceutical substances in the environment - a review, Chemosphere 36 (1998) 357-394.

[11] Z.T. Liu, H.Y. Zhang, Y.L. Liu, Effect of electron irradiation on nitrofurans and their metabolites, Radiat. Phys. Chem. 76 (2007) 1903-1905.

[12] B. Liang, H.Y. Cheng, D.Y. Kong, S.H. Gao, F. Sun, D. Cui, F.Y. Kong, A.J. Zhou W.Z. Liu, N.Q. Ren, W.W. Wu, A.J. Wang, D.J. Lee, Accelerated reduction of chlorinated nitroaromatic antibiotic chloramphenicol by biocathode, Environ Sci. Technol. 47 (2013) 5353-5361.

[13] A.J. Wang, D. Cui, H.Y. Cheng, Y.Q. Guo, F.Y. Kong, N.Q. Ren, W.M. Wu, A membrane-free, continuously feeding, single chamber up-flow biocatalyzed electrolysis reactor for nitrobenzene reduction, J. Hazard. Mater. 199-200 (2012) 401-409.

[14] A.J. Wang, H.Y. Cheng, B. Liang, N.Q. Ren, D. Cui, N. Lin, B.H. Kim, K. Rabaey, Efficient reduction of nitrobenzene to aniline with a biocatalyzed cathode, Environ. Sci. Technol. 45 (2011) 10186-10193.

[15] Y. Mu, R.A. Rozendal, K. Rabaey, J. Keller, Nitrobenzene removal in bioelectrochemical systems, Environ. Sci. Technol. 43 (2009) 8690-8695.

[16] Y. Mu, J. Radjenovic, J.Y. Shen, R.A. Rozendal, K. Rabaey, J. Keller, Dehalogenation of iodinated X-ray contrast media in a bioelectrochemical system, Environ. Sci. Technol. 45 (2011) 782-788.

[17] J. Radjenovic, M.J. Farre, Y. Mu, W. Gernjak, J. Keller, Reductive electrochemical remediation of emerging and regulated disinfection byproducts, Water Res. 46 (2012) 1705-1714.

[18] D. Cui, Y.Q. Guo, H.S. Lee, H.Y. Cheng, B. Liang, F.Y. Kong, Y.Z. Wang, L.P. Huang M.Y. Xu, A.J. Wang, Efficient azo dye removal in bioelectrochemical system and post-aerobic bioreactor: optimization and characterization, Chem. Eng. J. 243 (2014) 355-363.

[19] F. Harnisch, C. Gimkiewicz, B. Bogunovic, R. Kreuzig, U. Schroder, On the removal of sulfonamides using microbial bioelectrochemical systems, Electrochem. Commun. 26 (2013) 77-80.

[20] F. Sun, H. Liu, B. Liang, R.T. Song, Q. Yan, A.J. Wang, Reductive degradation of chloramphenicol using bioelectrochemical system (BES): a comparative study of abiotic cathode and biocathode, Bioresour. Technol. 143 (2013) 699-702.

[21] Q. Wen, F.Y. Kong, H.T. Zheng, J.L. Yin, D.X. Cao, Y.M. Ren, G.L. Wang, Simultaneous processes of electricity generation and ceftriaxone sodium degradation in an air-cathode single chamber microbial fuel cell, J. Power Sources 196 (2011) 2567-2572.

[22] Q. Wen, F.Y. Kong, H.T. Zheng, D.X. Cao, Y.M. Ren, J.L. Yin, Electricity generation from synthetic penicillin wastewater in an air-cathode single chamber microbial fuel cell, Chem. Eng. J. 168 (2011) 572-576.

[23] H. Song, W. Guo, M.L. Liu, J.H. Sun, Performance of microbial fuel cells on removal of metronidazole, Water Sci. Technol. 68 (2013) 2599-2604.

[24] N. Oturan, J. Wu, H. Zhang, V.K. Sharma, M.A. Oturan, Electrocatalytic destruction of the antibiotic tetracycline in aqueous medium by electrochemical advanced oxidation processes: effect of electrode materials, Appl. Catal. B: Environ. 140 (2013) 92-97.

[25] K.P. de Amorim, L.L. Romualdo, L.S. Andrade, Electrochemical degradation of sulfamethoxazole and trimethoprim at boron-doped diamond electrode: 
performance, kinetics and reaction pathway, Sep. Purif. Technol. 120 (2013) 319-327.

[26] D. Kong, B. Liang, D.-J. Lee, A. Wang, N. Ren, Effect of temperature switchove on the degradation of antibiotic chloramphenicol by biocathode bioelectrochemical system, J. Environ. Sci. 26 (2014) 1689-1697.

[27] G.Y. Li, S.G. Wan, T.C. An, Efficient bio-deodorization of aniline vapor in a biotrickling filter: metabolic mineralization and bacterial community analysis, Chemosphere 87 (2012) 253-258.

[28] B. Liang, H.Y. Cheng, J.D. Van Nostrand, J.C. Ma, H. Yu, D.Y. Kong, W.Z. Liu, N.Q Ren, L.Y. Wu, A.J. Wang, D.J. Lee, J.Z. Zhou, Microbial community structure and function of nitrobenzene reduction biocathode in response to carbon source switchover, Water Res. 54 (2014) 137-148.

[29] B. Liang, G.L. Wang, Y.F. Zhao, K. Chen, S.P. Li, J.D. Jiang, Facilitation of bacterial adaptation to chlorothalonil-contaminated sites by horizontal transfer of the chlorothalonil hydrolytic dehalogenase gene, Appl. Environ. Microbiol. 77 (2011) 4268-4272.

[30] J. Vila, J. Ruiz, F. Marco, A. Barcelo, P. Goni, E. Giralt, T.J. Deanta, Association between double mutation in gyrA gene of ciprofloxacin-resistant clinica isolates of Escherichia coli and MICs, Antimicrob. Agents Chemother. 38 (1994) 2477-2479.
[31] J.A. Elliott, R.R. Facklam, Antimicrobial susceptibilities of Lactococcus lactis and Lactococcus garvieae and a proposed method to discriminate between them, J. Clin. Microbiol. 34 (1996) 1296-1298.

[32] J.C. Ma, A.M. Ibekwe, X. Yi, H.Z. Wang, A. Yamazaki, D.E. Crowley, C.H. Yang, Persistence of Escherichia coli 0157:H7 and its mutants in soils, PLoS One 6 (2011) e23191, http://dx.doi.org/10.1371/journal.pone.0023191.

[33] P. Chenna Rohini Kumar, G.R.K. Naidu, K. Balaji, C. Suresh Reddy, Electrochemical behaviour and analysis of furazolidone in pharmaceutical formulations, Int. J. Life Sci. Biotechnol. Pharm. Res. 1 (2012) 95-100.

[34] L. Fotouhi, M. Nemati, M.M. Heravi, Electrochemistry and voltammetric determination of furazolidone with a multi-walled nanotube composite film-glassy carbon electrode, J. Appl. Electrochem. 41 (2011) 137-142.

[35] Z.T. Liu, L.H. Song, C.D. Yang, H.Y. Zhang, Degradation of 3-amino-2oxazolidinone (AOZ) in aqueous solutions by electron beam irradiation, Nucl. Instrum. Methods B 243 (2006) 109-112.

[36] N. Bao, J. Sun, Z.T. Wei, D. Ma, F. Liu, J. Wang, Degradation of biorefractory furaltadone in aqueous solution by ozonation, J. Chem. Technol. Biotechnol. 83 (2008) 1347-1352. 